\section{PRELÚDIO PARA UMA FILOSOFIA DO JOGO: A DEFINIÇÃO DE BERNARD SUITS}

\author{
PRELUDE FOR A PHILOSOPHY OF GAMES: BERNARD SUITS'S \\ $D E F I N I T I O N$ C
}
PRELUDIO PARA UNA FILOSOFÍA DEL JUEGO: LA DEFINICIÓN DE BERNARD SUITS C

https://doi.org/10.22456/1982-8918.113927

\section{Marcus Vinícius Simões de Campos*<camposmvs@gmail.com> \\ Odilon José Roble* <roble@fef.unicamp.br>}

*Universidade Estadual de Campinas (Unicamp). Campinas, SP, Brasil.
Resumo: Parte-se do pressuposto de que o filósofo americano Bernard Suits é central para a filosofia do esporte, especialmente na literatura internacional. Sua extensa obra oferece uma teoria do Jogo original e ainda não explorada na Educação Física brasileira. Suits distingue o fenômeno Jogo (game) da experiência do jogar (play), além de propor uma definição analítica de Jogo que é aqui apresentada aos modos de um prelúdio de sua teoria. Discute-se que, do ponto de vista de uma filosofia analítica, avança-se na metafísica do Jogo, ou em uma efetiva filosofia do Jogo, quando mobilizamos a definição de Suits de jogar um Jogo (game-playing). Reconhecem-se ainda subsídios analíticos distintos da definição intencionalmente vaga de famílias de jogos da herança wittgensteiniana, influente nas concepções brasileiras. Acredita-se que tais recursos fornecem renovado material para os estudos do Jogo na filosofia do esporte e Educação Física brasileiras, nos domínios da metafísica, lógica, epistemologia e axiologia.

Palavras chave: Teoria do Jogo. Filosofia. Esportes. Bernard Suits.
Recebido em: 11 mai. 2021 Aprovado em: 05 nov. 2021 Publicado em: 28 dez. 2021

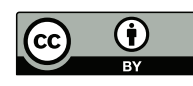

Este é um artigo publicado sob a licença Creative Commons Atribuição 4.0 Internacional (CC BY 4.0). elSSN: 1982-8918 


\section{INTRODUÇÃO ${ }^{1}$}

Parte-se do pressuposto de que o filósofo americano Bernard Suits é autor central para toda a filosofia do esporte, especialmente na forma como é articulada nas associações internacionais. Sua extensa obra oferece uma teoria do $\mathrm{Jogo}^{2}(\text { game })^{3}$ original e ainda pouco explorada na Educação Física brasileira, uma vez que discute ativamente a distinção entre Jogo e a experiência do jogar (play).

Para avançar nesta questão, propomos como objetivo analisar a definição de jogar um Jogo (game-playing) tal qual em Bernard Suits, com vistas a localizar sua concepção metafísica de Jogo. Precisamos, para evitar equívocos, observar que Suits não define o que é o Jogo, mas jogar um Jogo. Mesmo assim, sua concepção nos fornece elementos essenciais sobre estes fenômenos.

Como consequência da análise da definição de Suits, este texto se configura como primeira iniciativa de introduzir a obra do filósofo no cenário brasileiro de forma analítica, bem como um prelúdio para futuras análises sobre o conceito de Jogo em língua portuguesa. Para tanto, propomos três seções. Primeiro, apresentamos a premissa do artigo: a indistinção na literatura em Educação Física entre os fenômenos do jogar e do jogo. Segundo, apresentamos Suits contra Wittgenstein e, como ponta de lança, discorremos sobre o projeto suitiano de contra-argumentar a afirmação de Wittgenstein de que os Jogos não podem ser definidos. Explora-se, conjuntamente, a noção de Wittgenstein a respeito dos jogos e sua semelhança de família influente em várias concepções que se espraiaram na tratativa do tema entre nós. Finalmente, analisa-se a definição suitiana da atividade de jogar um Jogo (game-playing), especialmente a partir da leitura de sua magnum opus, o Grasshopper ${ }^{4}$.

\section{EVITANDO EQUÍVOCOS: ENTRE O “JOGO” E O “JOGAR”}

Na literatura brasileira em Educação Física encontramos, via de regra, uma indistinção entre os termos "jogar"5 e "jogo". Assumindo que tal falta de distinção é frequente e que podemos, do ponto de vista filosófico, refletir sobre as consequências conceituais desse problema, elegemos essa premissa como norteadora deste estudo.

Abstendo-nos da impossível tarefa de capturar todo uso do termo no campo da Educação Física, tal premissa, derivada da consulta de alguns trabalhos teóricos

\footnotetext{
1 Artigo elaborado com base na tese defendida pelo primeiro autor: CAMPOS, Marcus Vinícius Simões de. Jogo e Bernard Suits: considerações para a Educação Física brasileira. 2020. 210 f. Tese (Doutorado em Educação Física), Faculdade de Educação Física, Universidade Estadual de Campinas, Campinas, 2020.

2 Optamos por utilizar o termo em maiúsculo como é comum em algumas traduções nas quais o conceito em questão é utilizado incondicionalmente na literatura, de forma a distingui-lo conceitualmente.

3 Apontaremos entre parentes, na primeira vez que forem mencionados, os termos como utilizados no original por Bernard Suits. Repetiremos ao longo do texto quando oportuno para ênfases.

4 Adotamos o termo Grasshopper quando mencionamos a principal obra de Suits, de 1978, The Grasshopper: Games, Life, and Utopia.

5 Notamos que o verbo to play em inglês recebe inúmeras formas de tradução. Encontramos sua tradução como brincar ou experiência lúdica. Optamos por jogar, que, como verbo, contempla precisamente nossa investigação, conservando uma relação direta com o Jogo. Isto posto, não afirmamos aqui sua incompatibilidade entre as traduções anteriores, mas consideramos que, para melhor caminharmos nessa relação conceitual, quando em relação ao fenômeno do Jogo, o brincar e a experiência lúdica são melhores representados pelo termo jogar. Contudo, é de igual importância destacar que, em Suits, "jogar um Jogo", tradução de game-playing, quando tomados simultaneamente, não necessariamente pressupõe o que na literatura geralmente se entende por jogar, brincar ou experiência lúdica, de forma autotélica. Em Suits (2017), é possível jogar ou participar de um Jogo.
} 
centrais na área sobre o tema, mas que não esgota ou captura todas as contribuições nesse campo, sugere subsídios suficientes e filosoficamente relevantes para concluirmos que uma significante parte da literatura brasileira tem desenvolvido suas pesquisas, assiduamente, designando jogo como seu objeto de estudo central, mas que, nos termos que aqui assumimos, discursam sobre jogar (BRUHNS, 1996; FREIRE, 2002; FREIRE; SCAGLIA, 2003; LEONARDO; SCAGLIA; REVERDITO, 2009; REVERDITO; SCAGLIA, 2009; SCAGLIA, 2003; SCAGLIA, 2011; SCAGLIA et al., 2013; SCAGLIA et al., 2015; SCAGLIA, 2017; GRILLO; RODRIGUES; NAVARRO, 2019).

Por outro lado, mesmo quando interessados no Jogo como entidade, especialmente na forma de jogos esportivos coletivos e elencando alguns elementos desse fenômeno, suas reflexões se desenvolvem sob tal indistinção, na maioria das vezes importando conceitos do jogar para a estruturação de suas concepções de Jogo.

Com efeito, sob o ponto de vista epistemológico, anuncia-se um problema considerável. Além do prejuízo da indistinção em si, ainda se identifica que a abordagem do conceito de Jogo, conjuntamente ao conceito de jogar, suscita uma carência ontológica (FEEZELL, 2010; CARLSON, 2011; REID, 2012; RYALL, 2016; KLEIN, 2018). Afinal, o ser da coisa, nesse caso, é o Jogo, cujas extensões podem se dar no jogar. Há um continuum entendimento na Educação Física (não só brasileira) entre a conexão de ambos os fenômenos, por diversas subdisciplinas de vertente humanísticas da área, das quais a filosofia do esporte se distingue (MEIER, 1981; VOSSEN, 2004).

Em língua inglesa, a diferença entre estes termos é, de certa forma, mais intuitiva, pois apresenta duas palavras de morfologia distintas: game para o substantivo, play para o verbo. Ora, se podemos considerar plausível que duas palavras de morfologias diversas possam produzir a intuição clara de dois conceitos distintos, é de se supor que a semelhança morfológica em língua portuguesa entre jogo e jogar possa induzir esta falta de distinção.

Nossa hipótese é que, como boa parte da produção intelectual em filosofia do esporte, campo do qual partimos, circula em língua inglesa, podemos ter um agravante no cenário brasileiro, estimulando uma produção desconectada da literatura internacional e apontando para um caminho no qual, quanto mais avança, mais torna intuitiva uma indistinção. Sem embargo, o prejuízo aqui indicado reside no campo ontológico, não linguístico. Um princípio básico da filosofia como modo de produção de conhecimento é sua tendência à universalidade dos conceitos, ao menos aqueles que se permitem ter um caráter mais abrangente, sendo necessária suas transposições epistemológicas para cada língua.

O Jogo, como conceito, é inescapavelmente um deles. Há toda uma sorte de jogos em culturas e línguas diversas, que tensionam os limites de uma concepção geral de Jogo. Mas isso é assunto próprio de pesquisas, por exemplo, no campo da antropologia cultural. Para a filosofia, as variações práticas de um conceito só reforçam sua constante teórica, desde que ela esteja bem identificada. Desse modo, a filosofia de Bernard Suits apresenta-se como um dos caminhos possíveis 
para estabilizar essa questão conceitual. A obra de Suits é frequente e fundante para a filosofia do esporte, de modo que sua definição de jogar um Jogo (gameplaying) aparece na literatura específica como um vetor central para esse campo de conhecimento (HOPSICKER; HOCHSTETLER, 2016; KRETCHMAR; TORRES; 2018; DEVINE; LOPEZ FRIAS, 2020).

\section{COMO PONTA DE LANÇA: SUITS CONTRA WITTGENSTEIN}

Filósofos do esporte têm encontrado na interpretação suitiana uma rica contribuição que, não estando isenta de críticas $^{6}$ (MCBRIDE, 1979; PADDICK, 1979; BERMAN, 2013; KRETCHMAR, 2019), exerce grande impacto dentro da área (KOBIELA; LOPEZ FRIAS; TRIVINO, 2019; DEVINE; LOPEZ FRIAS, 2020;). A riqueza por trás dos estudos teóricos na filosofia do esporte sobre esse tema deve muito ao último século, que passou a compreender duas concepções radicalmente distintas e filosoficamente incompatíveis na metafísica dos Jogos: uma formulada pelo filósofo austríaco Ludwig Wittgenstein e outra por Bernard Suits.

A definição de Suits é uma resposta à afirmação de Wittgenstein de que não é possível definir os Jogos (games). Já no prefácio do Grasshopper, Suits oferece ao leitor a orientação do livro, distinguindo-a de um esforço sociológico ou psicológico, assim como a proposta de uma contribuição direta que o autor denomina teoria dos Jogos. Como afirma Suits (1978), sua obra orienta-se por uma análise filosófica no sentido tradicional da palavra. Seu principal objetivo é formular uma definição e seguir as implicações desta, independentemente do caminho que suas potenciais objeções ofereçam, uma vez que "[...] um dos mais assertivos (e seguramente o mais exótico dos) porta-vozes da atitude antidefinicionista, [Wittgenstein] celebrizou-se por ter distinguido a tentativa de definir os jogos como uma perfeita ilustração da futilidade de procurar definir seja o que for" (SUITS, 2017, p. 32).

Wittgenstein $(1999)^{7}$ desafiou a tradição filosófica do significado como representação (algo exterior à proposição, alocado no mundo ou na consciência), movendo-se para uma visão que toma esse significado como o cerne da investigação (BILETZKI; MATAR, 2020) e, embora possamos esclarecer conceitos como Verdade, Justiça ou mesmo Jogos, não podemos defini-los. O filósofo identificou atrás de cada tentativa de delimitação a forma platônica de corresponder a uma essência. Para tanto, um dos principais exemplos para justificar sua teoria foram os jogos, de modo que, sobre eles, Wittgenstein (1999, p. 52) escreve:

§66 - Considere, por exemplo, os processos que chamamos de jogos.
Refiro-me a jogos de tabuleiros, de cartas, de bolas, torneios esportivos
etc. O que é comum a todos eles? Não diga: 'Algo deve ser comum a eles,
senão não se chamariam jogos - mas veja se algo é comum a todos. -
Pois, se você os contemplar, não verá na verdade algo que seja comum
a todos, mas veja semelhanças, parentescos, e até toda uma série deles.
Como disse: não pense, mas veja! [...] §67 - Não posso caracterizar melhor
essas semelhanças do que com a expressão 'semelhanças de família', pois

6 Devido aos limites deste artigo, nos abstemos explorar as possíveis críticas à obra de Suits.

7 A data de publicação original do Investigações Filosóficas de Wittgenstein é 1953. 
assim se envolvem e se cruzam as diferentes semelhanças que existem entre os membros de uma família: estatura, traços fisionômicos, cor dos olhos, o andar, o temperamento, etc., etc. - E digo: os jogos formam uma família. ${ }^{8}$

Embora dividam uma pluralidade de aspectos em comum, não há entre familiares uma característica - ou conjunto de características - compartilhada inexoravelmente por todos. Corroborando a versão dos jogos como membros de uma família, muitos autores defendem a impossibilidade de capturarmos o que estes são, embora seja importante destacar que, muitas vezes, parece tácito que estejam mais induzidos a investigar o jogar (play).

Tal raciocínio semeou interessantes abordagens sobre o Jogo na Educação Física brasileira, em vários núcleos. Por exemplo, Scaglia (2003), Leonardo, Scaglia e Reverdito (2009), Scaglia et al. (2015) ou Scaglia et al. (2013) podem ser associados a uma taxionomia dos jogos coletivos como família, concepção diretamente influenciada por Wittgenstein. Todo um conjunto de publicações nacionais e internacionais na pedagogia do esporte sugere uma concepção ortodoxa corrente dos jogos como sistemas complexos, derivada da acepção de teorias antidefinicionistas como um eixo central de produção nessa subdisciplina (GARGANTA, 1998; GARGANTA; GRÉHAIGNE, 1999; FREIRE; SCAGLIA, 2003; LEONARDO; SCAGLIA; REVERDITO, 2009; GRÉHAIGNE; RICHARD; GRIFFIN, 2008; REVERDITO; SCAGLIA, 2009; SCAGLIA, 2011; SCAGLIA et al., 2013; SCAGLIA et al., 2015; SCAGLIA, 2017). Scaglia et al. (2013) ainda oferecem uma leitura que, para os autores, se caracteriza como a ontologia dos jogos esportivos coletivos, isto é, sua estrita relação com o Jogo, mas indiscriminada da experiência de jogar (play). Ademais, enquanto os autores usam o termo ontologia de modo a abarcar dentro do conceito "aquilo que é em si (último e irredutível)" (SCAGLIA et al., 2013, p. 228), não fica claro como podem fazê-lo do ponto de vista filosófico e, ao mesmo tempo, se sustentarem em uma definição de família.

Tais autores oferecem uma leitura do Jogo associada às teorias da complexidade, autopoiese ou sistêmica, expondo caminhos profícuos para o exercício pedagógico que rompa com o paradigma analítico e cartesiano, contra os quais suas abordagens se mobilizaram. Isto porque tais teorias oferecem uma nova forma de enxergar os seres humanos, suas relações consigo mesmos, com os outros e com o mundo. Uma vez inseridas na literatura em pedagogia do esporte, tais teorias representam uma iniciativa fundamental para o desenvolvimento de uma concepção interacionista do processo de ensino-aprendizagem-treinamento (GALATTI et al., 2014; SCAGLIA; REVERDITO, 2016).

Todavia, quanto à ontologia dos jogos, a transposição das teorias anteriormente mencionadas (SCAGLIA, 2003; LEONARDO; SCAGLIA; REVERDITO, 2009; SCAGLIA et al., 2015; SCAGLIA et al., 2013) para uma conceituação ontológica parece problemática, pois o leitor se vê ausente de uma concepção na qual o sistema complexo que todo Jogo é se distinga, de fato, de outros sistemas complexos. Enquanto as teorias da complexidade, autopoiese ou sistêmica oferecem novas maneiras de 
se olhar para as relações dos seres humanos entre si e com o mundo, corre-se o risco de redundância ${ }^{9}$ ao se projetar uma ontologia do Jogo a partir de teorias que, no limite, podem ser aplicadas a outras atividades como tocar um instrumento, pintar ou trabalhar. Mais uma vez temos um exemplo do problema da indistinção. Em geral, ninguém duvidaria da frase genérica que "o Jogo propicia relações humanas", mas do ponto de vista filosófico, a frase é ilógica, pois, o Jogo pressupõe relações humanas ${ }^{10}$. Filosoficamente correto seria sugerir que o Jogo expressa relações humanas e que o jogar pode, eventualmente, alterá-las.

Contrário à impossibilidade de definir os Jogos, Suits (1977) apresenta no Grasshopper uma concepção que objetiva contemplar todas as atividades que se acomodem nesse conceito. É importante destacar que ele adverte para a possível confusão linguística que tal tentativa possa despertar. Não se trata de compreender o termo Jogo a partir do uso corrente nas diferentes línguas existentes, ou como este é utilizado e articulado de forma corriqueira e polissêmica no cotidiano das diversas culturas. Ao contrário, trata-se de encontrar, analiticamente, sua estrutura mais elementar. Com isso, não se tem uma asserção definitiva sobre o que é o Jogo, mas uma proposta. Embora suficientemente estável para permitir um tratamento filosófico, tal proposta pode ser revista a qualquer momento a partir de contra-argumentos. Ao contrário, uma definição vaga parece sempre se ajustar às críticas, paradoxalmente, perpetuando-se e impedindo um exercício estritamente filosófico.

Suits notou que, embora reconheça a impecabilidade do conselho de Wittgenstein - "[...] não pense, mas veja!", quando se tratou de Jogos, o filósofo austríaco parece ter visto muito pouco (SUITS, 2017, p.32). Respondendo a Wittgenstein, Suits utiliza como método a filosofia analítica, de forma a compreender o conceito de Jogo em suas condições necessárias e suficientes. Em outras palavras, a definição de Jogo de Suits é suficientemente estreita para excluir aquilo que não é Jogo, ao passo que é necessariamente ampla para acomodar tudo o que se considera como Jogo. Ao apresentar as condições necessárias e suficientes para jogar um Jogo (game-playing), Suits não só defendeu uma definição dos Jogos (games), mas desferiu um golpe certeiro contra a filosofia de Wittgenstein (HURKA, 2014).

Diversos autores caracterizam o Grasshopper como uma peça formidável de boa filosofia analítica, pois Suits encontrou o que é comum entre os Jogos uma vez que foi mais profundo e abstrato que Wittgenstein (HURKA, 2014, 2019; KRETCHMAR, 2014; RYALL, 2016). Com efeito, sua análise dos Jogos "[...] fornece um exemplo clássico do tipo de pensamento cuidadoso, sistemático e baseado em lógica que caracteriza muitos trabalhos analíticos" (KRETCHMAR, 2014, p. 43, tradução nossa).

\section{DEFININDO A ATIVIDADE DE JOGAR UM JOGO (GAME-PLAYING)}

Primeiramente formulada por Suits em 1966, mas recebendo uma importante atualização em 1978, sua definição de jogar um Jogo (game-playing) tem sido um eixo epistêmico para boa parte das discussões entre os filósofos do esporte sobre a

9 Isto não implica que tais teorias não apresentem uma forma fundamental de se compreender as relações humanas, mas que, do ponto de vista filosófico, uma ontologia do Jogo deve tomar tal ponto de vista como dado.

10 Mesmo em exemplos de jogar consigo mesmo há um nível de relação abstrato acionado pelo desafio do Jogo. 
natureza dos Jogos (games). Na sua forma mais resumida, para Suits (2017, p. 82) "[...] jogar um jogo é procurar voluntariamente superar obstáculos desnecessários". Suits (2017, p. 82-83) também nos oferece uma definição mais detalhada, da qual a anterior se deriva:

Jogar um jogo é procurar alcançar um estado de coisas específico [fim prelusório], usando apenas meios permitidos pelas regras [meios lusórios], sendo que as regras proíbem o uso de meios mais eficientes em favor de meios menos eficientes [regras constitutivas], e aceitando-se as regras somente porque estas tornam possível essa actividade [atitude lusória].

Suits apresenta quatro condições necessárias e suficientes para se jogar um Jogo: fim prelusório (prelusory goal), meios lusórios (lusory means), regras constitutivas (constitutive rules) e atitude lusória (lusory attitude). Sendo assim, de sua definição de jogar um Jogo, pode-se derivar sua concepção metafísica do fenômeno do Jogo. Se, por um lado, Suits (2017) oferece condições necessárias e suficientes para se jogar um Jogo, o filósofo também oferece uma análise estrutural do fenômeno (HURKA, 2017).

Nota-se que sua concepção de Jogo não reflete uma atividade que detenha tais elementos de forma desconexa. Ao contrário, segundo Hurka (2017), que interpretou a definição de Suits a partir do que considera os três elementos estruturais (sendo os meios lusórios consequência das regras constitutivas), a atitude lusória se relaciona diretamente com as regras, enquanto estas, diretamente ao fim prelusório. Do encaixe entre tais elementos é que se deriva a força filosófica de Suits e sua concepção metafísica de tal atividade (HURKA, 2017). Ademais, por ser uma atividade, e não uma experiência, os Jogos são problemas convencionais ou artificiais que criamos, os quais podemos ou não experenciar de forma lúdica (jogar) (KRETCHMAR, 2008).

Embora possa parecer que os termos usados por Suits (2014) sugiram uma conflação entre os fenômenos do jogar e do Jogo, apresentando uma relação contínua entre eles, é importante desassociar jogar (na definição suitiana) de uma atividade autotélica. O termo play ${ }^{11} \mathrm{em}$ inglês é utilizado irrestritamente, não necessariamente como verbo que indica atividades associadas ao jogar, a experiência lúdica ou o brincar. Nas próprias palavras de Suits (2017, p. 289), "[...] não nos deveríamos preocupar com a palavra «jogar» quando esta funciona como sinónima de palavras como «actuar», «operar» ou «participar em»" (SUITS, 2017, p. 289).

Suits (2014) não compreende o caráter autotélico como uma condição necessária para se jogar um Jogo (game-playing) e como parte de sua definição. De acordo com Morgan (2008), o jogar e o jogo não são logicamente independentes, mas logicamente incompatíveis, isto é, a partir do método analítico, é possível se chegar a argumentos lógicos que sustentem ambos os fenômenos de um ponto de vista autônomo, mesmo que estes combinem-se eventualmente na experiência do jogador. Sendo assim, tanto é possível participar, atuar, operar em um Jogo (game), como é possível jogá-lo (play) de forma autotélica.

Esta noção pode ser ilustrada especialmente na descrição do ofício dos atletas profissionais. Embora possamos tomar a atividade de competir em um evento como uma atividade autotélica, mais seguro seria assumi-la em termos como participar,

11 Consultar a nota de rodapé 4. 
atuar, operar naquele determinado esporte, pois não temos, de partida, a condição autotélica. Em termos simples, o atleta profissional pode ter outros interesses em questão que instrumentalizem a sua participação na competição. Suits oferece uma definição que dá conta de contemplar a atividade de se envolver com um Jogo mesmo como forma de trabalho, no sentido moderno do termo.

A coerência interna da definição de Suits faz com que o uso corrente da linguagem nas diversas culturas não seja o fio condutor de sua análise filosófica, mas as condições necessárias e suficientes da sua definição. Isso pode ser identificado no modo como atividades muitas vezes diferentes se acomodam na sua definição. De acordo com Hurka (2019, p. 16, tradução nossa), a coerência interna de sua definição e a forma como Suits descreve seus elementos engloba de modo harmonioso inúmeras atividades que, na chave wittgeinsteiniana, poderíamos descrever como apenas compartilhando semelhanças de família, pois Suits confere "[...] à sua análise uma unidade impressionante e até uma beleza, pois combina três elementos - um fim, regras e uma atitude - em um todo coerente e integrado."

Pensemos em cada um desses elementos, utilizando, para isto, exemplos do meio esportivo, uma vez que, para Suits (2007), todos os esportes se alocam na categoria de Jogo (game $)^{12}$. Na versão reduzida de sua definição, Suits (2014) demonstra a imposição de se admitir obstáculos desnecessários para se jogar um Jogo. Sendo todos os Jogos atividades direcionadas a fins, estes obstáculos desnecessários só existem em relação a tais fins. Nesse sentido, a definição dos jogos de Suits engloba diretamente aquilo que ele chamou de fim prelusório, o primeiro elemento de sua definição.

O fim prelusório, por exemplo, do golfe, é o de colocar uma pequena bola dentro de um buraco igualmente pequeno, do basquetebol, fazer com que a bola laranja passe por um aro circular, encontrado a 3,05 metros de altura. Para Suits (2014), tomando aqui uma interpretação recorrente, o fim prelusório pode ser atingido sem que o agente esteja participando do Jogo, ou seja, sem que esse abdique dos meios mais eficientes em prol dos ineficientes. Mas para que possamos dizer que ele está efetivamente no Jogo, inúmeros obstáculos se apresentam: os jogadores não podem colocar a bola com as mãos no buraco do golfe ou utilizar escadas para colocar uma bola laranja em um aro circular a 3,05 metros de altura no basquete.

Os fins prelusórios de cada uma dessas modalidades esportivas exemplificadas podem ser atingidos por uma miríade de possibilidades. Entretanto, assumir qualquer uma das estratégias anteriores não condiz com os comportamentos adotados por atletas em meio às partidas de cada um desses esportes. Dessa forma, o fim prelusório "[...] pode ser descrito antes, ou independentemente de qualquer jogo de que possa fazer já, ou vir a fazer, parte" (SUITS, 2017, p. 75). Por essa razão, são fins do tipo pré, ou seja, analiticamente, eles vêm antes do objeto central.

Além do fim prelusório, Suits menciona outro fim diretamente relacionado com sua definição: o fim lusório (lusory goal). O fim lusório, mesmo não estando presente

12 Embora o próprio Suits reformule sua concepção de que todos os esportes são Jogos (SUITS, 1988), diversos filósofos do esporte compreendem que suas primeiras formulações sobre essa relação são mais coerentes (MEIER, 1988; KRETCHMAR, 2019). Conservaremos a concepção de que todos os esportes são Jogos, assim como é amplamente aceito na literatura. 
de maneira explícita na definição, apresenta-se implicitamente, pois é identificado como o vencer o Jogo. As simples ações como colocar uma bolinha dentro de um também pequeno buraco ou fazer com que uma bola laranja passe por um aro circular a 3,05m de altura transformam-se em elementos constitutivos de um esporte à medida que a atitude lusória se apresenta implicitamente.

Enquanto fora do Jogo consideramos inúmeras formas de realizar o que anunciam os fins prelusórios, tais fins só ganham sentido quando jogamos os Jogos que os preveem e, mais que somente estar nos Jogos, tentamos vencê-los. Assim, Suits (2017, p. 75) distingue o fim prelusório do fim lusório, pois o primeiro é descrito como "[...] um estado de coisas específico alcançável [de diferentes formas possíveis, eventualmente mais eficientes que aquelas que respeitam as regras; enquanto] ao omitir como se há de realizar o estado de coisas em causa, evita-se a confusão entre este fim e o fim de vencer". Notemos aqui como nesse esforço exemplar de filosofia analítica, Suits vai isolando, lenta e indefectivelmente, o fenômeno do Jogo, afastando-se de modo cabal da noção genérica de que tudo é um Jogo ou que o Jogo está em tudo.

Além do desejo de vencer, os fins lusórios também envolvem as formas possíveis de manifestação desse desejo. Avançando nos mesmos exemplos, os meios para se atingir os respectivos fins prelusórios do golfe e do basquetebol são tão somente aqueles permitidos pelas regras constitutivas (constitutive rules). Assim, Suits (2017, p. 76) também define os meios lusórios como "[...] meios permitidos (lícitos ou legítimos) na tentativa de alcançar fins prelusórios."

Grande parte da nossa afeição por Jogos vem do fato deles serem repletos de dificuldades, desafios e obstáculos. Suits (2017, p. 82) explora os Jogos como atividades que, para se chegar aos fins prelusórios, acrescentam dificuldades - ou na sua própria nomenclatura: "obstáculos desnecessários". Segundo a definição suitiana, essa é uma condição para todos os Jogos, pois as regras constitutivas sempre têm como função determinar meios ineficientes específicos em relação ao fim prelusório, sendo essa uma condição necessária que deriva da combinação de tais elementos (HURKA, 2019). Consequentemente, do ponto de vista da coerência interna da definição de Suits, se faz importante notar que a ineficiência nos Jogos é compreendida em relação ao fim prelusório, de modo que essa ineficiência denota os Jogos como um fenômeno de certa dificuldade artificial a ser superada.

Os obstáculos em um Jogo podem se manifestar de diferentes formas, por uma variedade de conteúdos. Podem se exteriorizar na forma de restrição do espaço, tempo, adversários, para citar alguns. São esses empecilhos que instituem o caráter ineficiente dos Jogos (se comparados a outras formas de se chegar ao fim prelusório). Suits (2017, p. 77-78) esclarece:

Convido-te [...] a pensares num qualquer jogo ao acaso. Agora identifica o seu fim prelusório: romper uma fita com o peito, derrubar um adversário, ou seja o que for. Creio que concordarás que a abordagem mais simples, ligeira e directa ao alcançar desse fim é sempre excluída a favor de uma abordagem mais complexa, mais difícil e mais indirecta.

A variedade de conteúdo dos obstáculos dos Jogos depende das regras constitutivas (constitutive rules), o terceiro elemento da definição de Suits. Por 
exemplo, no golfe, seria uma tarefa extremamente simples colocar uma bola dentro de um buraco, não fosse a necessidade de utilizar para essa tarefa aquilo o que o antigo primeiro-ministro Britânico Winston Churchill descreveu como "implemento mal concebido para a finalidade"13. As regras constitutivas têm exatamente essa função: ao delimitarem os meios, determinam quais comportamentos (e os meios relacionados a eles) podem ser utilizados para praticar aquele determinado Jogo, de modo a implementar obstáculos desnecessários à tarefa de atingir o fim prelusório.

Grosso modo, as regras constitutivas têm duas funções: nomear o fim prelusório e determinar os meios lusórios para alcançá-lo. Sendo assim, as regras constitutivas de um Jogo diferem de outras regras presentes em atividades diversas, pois carregam no cerne do seu sentido a exigência de que os meios construídos por elas para se chegar ao fim prelusório sejam, em geral, menos eficientes do que seriam na sua ausência (KRETCHMAR, 2019). Portanto, Suits (2017, p. 78) define as regras constitutivas como: "[...] regras que proíbem o uso dos meios mais eficientes para alcançar um fim prelusório".

Uma vez especificados o fim prelusório e os meios permitidos para atingi-lo, os jogadores podem alcançar tal fim da forma mais eficiente possível, desde que adotem ações prescritas pelas regras constitutivas. Suits (2017, p. 76) define os meios lusórios por aqueles "[...] que são permitidos (lícitos ou legítimos) na tentativa de alcançar fins prelusórios". Utilizando o próprio exemplo de Suits, propositadamente absurdo, temos que um meio extremamente eficiente para atingir o fim prelusório do boxe, que é o nocaute (ter seu oponente no chão por ao menos dez segundos), seria atirar com uma arma de fogo na cabeça do adversário. Contudo, nos Jogos, só é permitido o uso dos meios prescritos pelas regras constitutivas (ainda que menos eficientes para atingir o fim prelusório), sendo a vitória dependente da observância dos seus agentes para com tais regras.

Empunhar uma arma durante uma luta de boxe é um meio mais eficiente de atingir seu fim prelusório, mas sua ilegitimidade se caracteriza pelo que Suits chama de meios ilusórios (illusory means). O disparate do exemplo de Suits cumpre a função de mostrar como não há margem para além das regras constitutivas e meios lusórios, contrapondo genialmente meios lusórios a meios ilusórios. No sentido filosófico analítico, executa assim o teste de falseabilidade das premissas, mantendo seu argumento como consistente ao desmontar a hipótese de falsificação.

Entrando no coração da matéria, Suits nos mostra que as regras constitutivas, ao delimitarem os meios permitidos para conquistar o fim prelusório, também indicam o grupo de habilidades (skills) que cada Jogo pretende testar. Com efeito, as regras constitutivas são responsáveis por construir barreiras artificiais que requerem um conjunto de habilidades compatíveis com tal dificuldade (TORRES, 2000) ${ }^{14}$. Colocado de outra forma, embora as regras constitutivas permitam que através dos meios lusórios os jogadores utilizem todas as formas possíveis de se atingir o fim prelusório, também restringem e moldam as formas de comportamento em cada Jogo.

\footnotetext{
13 Exemplo de Simon, Torres e Hager (2015).

14 Em complemento, a artificialidade dos meios lusórios cria um ambiente em que não se pode desprezar o acaso, de ocorrência possível e até comum em competições de diversos esportes.
} 
Para que o Jogo ocorra e os três elementos anteriores se interconectem, se faz necessária, ainda, a atitude lusória (lusory atitude). As regras constitutivas têm sido referidas como elemento principal da definição suitiana e, por muito tempo, levado o crédito pela originalidade da teoria do autor. Autores como Reid (2012) afirmam que os outros três elementos de sua definição (fins, meios e atitude lusória) dependem das regras constitutivas para existir. Contudo, há um esforço em analisar outros elementos da obra de Suits presente na literatura com maior cuidado, de modo que há uma ênfase recente direcionada ao conceito de atitude lusória (MCLAUGHLIN, 2008; KRETCHMAR, 2017).

Este último elemento é descrito, por alguns autores, como o mais complexo e importante da definição (CARLSON, 2014). A atitude lusória dá sentido a todos os outros elementos e os une. Nos Jogos, não há nenhuma produção intencional além do próprio Jogo, ou seja, os Jogos são criados simplesmente para superação de seus obstáculos. Assim, são dotados de uma ineficiência intrínseca que os difere das atividades instrumentais. A atitude lusória, assim, é o reconhecimento e consentimento de uma atividade menos eficiente para se atingir o fim desejado.

Suits (2017) propõe como contraponto do Jogo o trabalho. Enquanto para atingir um determinado fim no trabalho utilizamos dos meios mais eficientes possíveis, ao passo que toda regra, protocolo ou diretrizes têm como objetivo final tornar aquele ofício mais eficiente (produtivo, seguro etc.), nos Jogos constroem-se obstáculos desnecessários tão somente para dificultar a obtenção daquele fim e, com isso, protagoniza-se uma atitude lusória. Sobre atitude lusória, o autor (SUITS, 2017, p. 81) define que "[...] trata-se da aceitação de regras constitutivas somente para que possa ter lugar a actividade tornada possível por essa aceitação". Mais uma vez temos que lembrar do esforço analítico de Suits e de sua recusa à posição de Wittgenstein, o que nos faz perceber nessa definição precedente não uma forma de pensamento circular, mas o zelo pela lógica interna de seu argumento, encerrando definição para o fenômeno (Jogo) e afastando, assim, a vagueza do princípio de família, da opção de Wittgenstein.

Uma forma de sintetizar a definição de Suits é acompanhar a descrição de Simon, Torres e Hager (2015). Os autores sugerem resumir a definição de Suits, lançando luz nos seus dois elementos principais: (1) regras constitutivas, as quais constroem obstáculos desnecessários para alcançar um fim específico, definindo meios permissíveis e proibidos para atingi-lo e (2) de modo que tais regras são aceitas pelos participantes somente para enfrentar o desafio criado. Quando resumida dessa forma, podemos admirar mais adequadamente a função específica dos dois principais elementos na definição de jogar um Jogo: "[...] é procurar voluntariamente superar obstáculos desnecessários." (SUITS, 2017, p. 82).

Finalmente, Suits (2017) também nos fornece uma explicação do que ele entende por atitude (attitude), que nos ajuda a reafirmar uma distinção clara entre o Jogo e o jogar na obra do autor. Há autores que relacionam o termo atitude com o jogar (play) (KLEIN, 2018), o que também é comum na literatura brasileira. Contudo, o jogar enquanto atitude não é sinônimo da atitude lusória (lusory attitude) na obra de Suits. A atitude lusória se relaciona com a aceitação de um tipo específico de regras 
(constitutivas e limitantes dos meios mais eficientes) que, podendo se relacionar e existir simultaneamente enquanto atividade lúdica e autotélica, não se reduz a tal experiência. Nas palavras de Suits (2017, p. 73-74):

[...] as regras dos jogos constituem um tipo assaz especial de regra, será necessário ter em conta um elemento a mais, nomeadamente, as atitudes dos jogadores enquanto jogadores. Acrescento «enquanto jogadores» porque não me refiro ao que poderia ser a atitude desta ou daquele jogador sob estas ou aquelas condições (por exemplo, a esperança de ganhar um prémio em dinheiro ou a satisfação de exibir destreza física perante um público entusiasta), mas à atitude sem a qual não é possível jogar um jogo. Chamaremos a esta atitude lusória (do latim ludus, jogo) [...] [ela] é o elemento que unifica os outros elementos numa única fórmula que apresenta de maneira bem-sucedida as condições necessárias e suficientes para que qualquer actividade seja um exemplo de jogar um jogo.

A distinção entre atitude lusória, ou seja, a atitude de jogar é, de certo modo, um salto na obra de Suits. Com ela, Suits identifica ambas as atitudes como logicamente distintas (SCHNEIDER, 2001). Ao jogar um Jogo, pode-se participar sem fundamentalmente ser tomado pela atitude de jogar (play), como, muitas vezes, ocorre com atletas profissionais.

Ainda que tais conceitos sejam, à primeira vista, complexos, argumentamos que o refinamento da lógica interna exige essa complexidade. Por outro lado, vale observar que, uma vez compreendida a relação entre os elementos constitutivos do conceito suitiano de jogar um Jogo, atingimos uma noção consistente do ponto de vista analítico. Com isso, abandonamos noções vagas ou generalistas, evitamos confusões conceituais entre fenômenos distintos e estabelecemos uma base para análises futuras aplicadas que possam se valer da segurança desses conceitos de partida. Pensamos que esse esforço da filosofia analítica é, assim, um componente essencial para uma teoria do Jogo.

\section{CONCLUINDO UMA URGÊNCIA}

Acreditamos que a obra de Bernard Suits é profícua e urgente para a área da Educação Física brasileira. Suas contribuições oferecem uma teoria do Jogo (game) original e ainda não explorada na área, que distingue esse fenômeno da experiência do jogar (play). Com vistas a desafiar a noção de jogos em Wittgenstein, que tem servido como um eixo central nas concepções ortodoxas sobre a temática na área, Suits abre uma outra linha de estudo, sobre o Jogo, que busca a análise filosófica analítica e rigorosa desse fenômeno, preocupando-se em compreendê-lo em si mesmo, sem o possível escapismo da ideia de imprecisão conceitual.

Compreendemos que a teoria suitiana dá conta de oferecer uma leitura sobre o Jogo que o distingue da experiência do jogar, bem como oferece subsídios filosóficos para que mais estudos sejam desenvolvidos em subdisciplinas da área da Educação Física, além de, evidentemente, na própria filosofia do esporte, em suas vertentes metafísica, lógica, epistemológica e axiológica. 


\section{REFERÊNCIAS}

BERMAN, Mitchell N. Sprints, sports and Suits. Journal of the Philosophy of Sport, v. 40, n. 1, p. 163-176, 2013. DOI: https://doi.org/10.1080/00948705.2013.785428

BILETZKI, Anat; MATAR, Anat. Ludwig Wittgenstein. Stanford Encyclopedia of Philosophy, 2020. Disponível em: https://plato.stanford.edu/. Acesso em: 13 jul. 2020.

BRUHNS, Heloisa T. O jogo nas diferentes perspectivas teóricas. Revista Motrivivência, ano VIII, n. 9, p. 28-43, 1996. DOI: https://doi.org/10.5007/\%25x

CARLSON, Chad. Games. In: TORRES, Cesar R. The Bloomsbury companion to the philosophy of sport. London: Bloomsbury, 2014. p. 359-360.

CARLSON, Chad R. The 'playing' field: attitudes, activities, and the conflation of play and games. Journal of the Philosophy of Sport, v. 38, n. 1, p. 74-87, 2011.

DEVINE, John W; LOPEZ FRIAS, Francisco J. Philosophy of sport. Stanford Encyclopedia of Philosophy, 2020. Disponível em: https://plato.stanford.edu/. Acesso em: 13 jul. 2020.

FEEZELL, Randolph. A pluralist conception of play. Journal of the Philosophy of Sport, v. 37, n. 2, p. 47-165, 2010. DOI: https://doi.org/10.1080/00948705.2010.9714773

FREIRE, João Batista. Jogo: entre o riso e o choro. Campinas: Autores Associados, 2002.

FREIRE, João Batista; SCAGLIA, Alcides José. Educação como prática corporal. São Paulo: Scipione, 2003.

GALATTI, Larissa Rafaela et al. Pedagogia do esporte: tensão na ciência e o ensino dos jogos esportivos coletivos. Revista da Educação Física, v. 25, n. 1, p.153-162, 2014.

GARGANTA, Julio. Para uma teoria dos jogos desportivos coletivos. In: GRAÇA, Amândio; OLIVEIRA, José (ed.). O ensino dos jogos desportivos. 3. ed. Porto: Faculdade de Ciências do Desporto e da Educação Física; Universidade do Porto, 1998. p. 11-25.

GARGANTA, Julio; GRÉHAIGNE, Jean-Francis. A abordagem sistêmica do jogo de futebol: moda ou necessidade. Movimento (Porto Alegre), v. 5, n. 10, p. 40-50, 1999. DOI: https:// doi.org/10.22456/1982-8918.2457.

GRÉHAIGNE, Jean-Francis; RICHARD, Jean-François; GRIFFIN, Linda L. Teaching and Learning: team sports and games. London: Routledge, 2008.

GRILLO, Rogério de M.; RODRIGUES, Gilson S.; NAVARRO, Eloisa R. Cultura lúdica: uma revisão conceitual à luz das ideias dos intelectuais dos estudos de jogo, cultura de jogo e cultura do lúdico. Arquivos em Movimento, v. 15, n. 2, p. 174-193, 2019.

HOPSICKER, Peter M.; HOCHSTETLER, Douglas. The future of sport philosophy in higher education kinesiology. Quest, v. 68, n. 3, p. 240-256, 2016.

HURKA, Thomas. Introduction. In: SUITS, Bernard. The grasshopper: games, life, and utopia. Orchard Park, NY: Broadview, 2014, p. IX-XXIII.

HURKA, Thomas. Suits on games. In: HURKA, Thomas (ed.). Games, sports, and play: philosophical essays. Oxford: Oxford University, 2019. p. 13-32.

KLEIN, Shawn E. The value of play and the good human life. Cultura, Ciencia y Deporte, $v$ 13, n. 38, p. 119-125, 2018. 
KOBIELA, Filip; LOPEZ FRIAS, Franscisco J.; TRIVINO, José Luis P. Bernard Suits' legacy: new inspirations and interpretations. Sport, Ethics and Philosophy, v. 13, n. 3-4, p. 271276, 2019.

KRETCHMAR, Robert S. A revised definition of games: and analysis of Grasshopper errors, omissions, and ambiguities. Sport, Ethics and Philosophy, v. 13, n. 3-4, p. 277-292, 2019.

KRETCHMAR, Robert S. Gaming up life: considerations for games expansions. Journal of the Philosophy of Sport, v. 35, n. 2, p. 142-155, 2008.

KRETCHMAR, Robert S. Sport, fiction, and the stories they tell. Journal of the Philosophy of Sport, v. 44, n. 1, p. 55-71, 2017.

KRETCHMAR, Robert S. The philosophy of sport and analytic philosophy. In: TORRES, Cesar R. (ed.). The Bloomsbury companion to the philosophy of sport. London: Bloomsbury, 2014.

KRETCHMAR, Robert S.; TORRES, Cesar R. Philosophy and physical activity. In: HOFFMAN, Shirl J; KNUDSON, Duane V. Introduction to kinesiology: studying physical activity. $5^{\text {th }}$. ed. Champaign: Human Kinetics, 2018. p. 91-116.

LEONARDO, Lucas; SCAGLIA, Alcides José; REVERDITO, Riller Silva. O ensino dos esportes coletivos: metodologia pautada na família dos jogos. Motriz, v. 15, n. 2, p. 236-246, 2009.

MCBRIDE, Frank. A critique of Mr. Suits' definition of game playing. Journal of the Philosophy of Sport, v. 6, n. 1, p. 59-65, 1979.

MCLAUGHLIN, Douglas. W. Reinventing the wheel: on games and the good life. 2008. 181 f. These (Doctor Kinesiology) -The Pennsylvania State University, Pennsylvania, 2008.

MEIER, Klaus V. On the inadequacies of sociological definitions of sport. International Review of Sport Sociology, v. 2, n. 16, p. 79-89, 1981.

MEIER, Klaus V. Triad trickery: playing with sport and games. Journal of the Philosophy of Sport, v. 15, n. 1, p. 11-30, 1988.

MORGAN, William J. Some further words on Suits on play. Journal of the Philosophy of Sport, v. 35, n. 2, p. 120-141, 2008.

PADDICK, Robert J. Review essay: the Grasshopper: games, life and utopia. Journal of the Philosophy of Sport, v. 6, n. 1, p. 73-78, 1979.

REID, Heather L. Introduction to the Philosophy of Sport. Lanham, MD: Rowman and Littlefield, 2012.

REVERDITO, Riller Silva; SCAGLIA, Alcides José. Pedagogia do esporte: jogos coletivos de invasão. São Paulo: Phorte, 2009.

RYALL, Emily. Philosophy of sport: key questions. London: Bloomsbury, 2016.

SCAGLIA, Alcides José. 0 futebol e os jogos/brincadeiras com os pés: todos semelhantes todos diferentes. 2003. 178 f. Tese (Doutorado em Educação Física) Faculdade de Educação Física, Universidade Estadual de Campinas, Campinas, 2003.

SCAGLIA, Alcides José. O futebol e as brincadeiras de bola: a família dos jogos de bola com os pés. São Paulo: Phorte, 2011. 
SCAGLIA, Alcides José. Pedagogia do jogo: o processo organizacional dos jogos esportivos coletivos enquanto modelo metodológico para o ensino. Revista Portuguesa de Ciências do Desporto, v. 17, n. S1A, p. 27-38, 2017.

SCAGLIA, Alcides José et al. O ensino dos jogos esportivos coletivos: as competências essenciais e a lógica do jogo em meio ao processo organizacional sistêmico. Movimento (Porto Alegre), v. 19, n. 4, p. 227-249, 2013. DOI: https://doi.org/10.22456/1982$\underline{8918.37893}$

SCAGLIA, Alcides José et al. Processo organizacional sistêmico, a pedagogia do jogo e a complexidade estrutural dos jogos esportivos coletivos: uma revisão conceitual. In: LEMOS, Katia Lucia M.; GREGO, Pablo J.; MORALES, Juan Carlos. 5o CONGRESSO INTERNACIONAL DOS JOGOS DESPORTIVOS, 5. 2015. [Anais...] Belo Horizonte: Casa da Educação Física, 2015. p. 43-61.

SCAGLIA, Alcides José; REVERDITO, Riller S. Perspectivas pedagógicas do esporte no século XXI. In: NISTA-PICCOLO, Vilma L.; MOREIRA, Wagner W. (eds.) Educação Física e Esporte no século XXI. Campinas: Papirus, 2016. p. 43-72.

SCHNEIDER, Angela Jo-anne. Fruits, apples, and category mistakes: on sport, games, and play. Journal of the Philosophy of Sport, v. 28, p. 151-159, 2001.

SIMON, Robert; TORRES, Cesar R.; HAGER, Paul. Fair play: the ethics of sport. Boulder, CO: Westview, 2015.

SUITS, Bernard. A cigarra filosófica: a vida é um jogo? Porto: Gradiva, 2017.

SUITS, Bernard. Appendix I: words on play. Journal of the Philosophy of Sport, v. 4, n. 1, p. 117-31, 1977.

SUITS, Bernard. The elements of sport. In: MORGAN, William J. Ethics in sport. Champaign, IL: Human Kinetics, 2007. p. 9-20.

SUITS, Bernard. The grasshopper: games, life and utopia. Toronto: University of Toronto, 1978.

SUITS, Bernard. The grasshopper: games, life, and utopia. Orchard Park, NY: Broadview, 2014.

SUITS, Bernard. Tricky triad: games, play, and sports. Journal of the Philosophy of Sport. v. 15 , n. 1 , p. 1-9, 1988.

TORRES, Cesar R. What counts as part of a game? A look at skills. Journal of the Philosophy of Sport, v. 27, n. 1, p. 81-92, 2000.

VOSSEN, Deborah P. The nature and classification of games. Avante, v. 10, n. 1, p. 53-69, 2004.

WITTGENSTEIN, Ludwig. Investigações filosóficas. São Paulo: Nova Cultural, 1999.

WITTGENSTEIN, Ludwig. Philosophical investigations. Oxford: Blackwell Publishing Ltd, 2009. 
Abstract: It is assumed that the American philosopher Bernard Suits is central to the philosophy of sport, especially in the international literature. His extensive work offers an original and unexplored theory of game in Brazilian Physical Education. Suits distinguishes the phenomenon of game from the experience of playing, in addition to proposing an analytical definition of game that is presented in the ways of a prelude to his theory. It is argued that, from the point of view of an analytical philosophy, one advances into the metaphysics of games, or an effective philosophy of the game, when Suits's definition of game-playing is mobilized. One also recognizes different analytical subsidies from the intentionally vague definition of game families of Wittgensteinian heritage, influential in Brazilian conceptions. It is believed that such resources provide new material for game studies in Brazilian sport philosophy and Physical Education, in the domains of metaphysics, logic, epistemology and axiology.

Keywords: Game theory. Philosophy. Sports. Bernard Suits.

Resumen: Se parte del supuesto de que el filósofo estadounidense Bernard Suits es fundamental para la filosofía del deporte, especialmente en la literatura internacional. Su extensa obra ofrece una teoría de juegos original y aún inexplorada en la Educación Física brasileña. Suits distingue el fenómeno juego (game) de la experiencia de jugar (play), además de proponer una definición analítica de juego, presentada aquí como un preludio a su teoría. Se discute que, desde el punto de vista de una filosofía analítica, se avanza en la metafísica del juego, o en una efectiva filosofía del juego, cuando movilizamos la definición de Suits de jugar un juego (game-playing). Se reconocen, además, subsidios analíticos distintos a la definición intencionalmente vaga de familias de juegos de la herencia wittgensteiniana, que tiene influencia en las concepciones brasileñas. Se cree que tales recursos brindan renovado material para los estudios del juego en la filosofía del deporte y en la Educación Física brasileñas, en los dominios de la metafísica, la lógica, la epistemología y la axiología.

Palabras clave: Teoría del Juego. Filosofía. Deportes. Bernard Suits. 


\section{LICENÇA DE USO}

Este é um artigo publicado em acesso aberto (Open Access) sob a licença Creative Commons Atribuição 4.0 Internacional (CC BY 4.0), que permite uso, distribuição e reprodução em qualquer meio, desde que o trabalho original seja corretamente citado. Mais informações em: https://creativecommons.org/licenses/by/4.0

\section{CONFLITO DE INTERESSES}

Os autores declararam que não existe nenhum conflito de interesses neste trabalho.

\section{CONTRIBUIÇÕES AUTORAIS}

Marcus Vinícius Simões de Campos: Análise literatura nacional e da obra de Bernard Suits, escrita.

Odilon José Roble: Análise literatura nacional e da obra de Bernard Suits, revisão.

\section{AGRADECIMENTOS}

Agradecemos a Francisco Javier Lopez Frias por sua imprescindível contribuição para com a tese de doutorado da qual este artigo se deriva, como consultor e membro titular da banca. Também gostaríamos de agradecer a ambos revisores por suas valorosas contribuições, precisamente no aprimoramento deste artigo.

\section{FINANCIAMENTO}

O presente trabalho foi realizado comapoio do Conselho Nacional de Desenvolvimento Científico e Tecnológico (CNPq) e da Coordenação de Aperfeiçoamento de Pessoal de Nível Superior - Brasil (CAPES) - Código de Financiamento 001.

\section{COMO REFERENCIAR}

CAMPOS, Marcus V. S.; ROBLE, Odilon J.; Prelúdio para uma filosofia do jogo: a definição de Bernard Suits. Movimento (Porto Alegre), v.27, p.e27075, jan./dez. 2021. Disponível em: https://seer.ufrgs.br/Movimento/article/view/113927. Acesso em: [dia] [mês abreviado]. [ano]. DOI: https://doi.org/10.22456/1982-8918.113927

\section{RESPONSABILIDADE EDITORIAL}

Alex Branco Fraga*, Elisandro Schultz Wittizorecki*, Ivone Job*, Lisandra Silva*, Mauro Myskiw *, Raquel da Silveira*

*Universidade Federal do Rio Grande do Sul, Escola de Educação Física, Fisioterapia e Dança, Porto Alegre, RS, Brasil. 